\title{
Solution Focused Brief Therapy Telemental Health Suicide Intervention
}

\author{
Benjamin T. Finlayson ${ }^{1}$ (D) Ethan Jones ${ }^{1} \cdot$ Jaclyn Cravens Pickens ${ }^{1}$
}

Accepted: 26 July 2021 / Published online: 10 August 2021

(C) The Author(s), under exclusive licence to Springer Science+Business Media, LLC, part of Springer Nature 2021

\begin{abstract}
One of the innumerable impacts of the coronavirus has been the change in how individuals provide services. For mental health providers, the pandemic required a sudden shift from in person to online service delivery. As therapists learn and embrace a new modality for providing therapy, crisis situations may present with some anxiety. With the pandemic increasing crisis situations for so many individuals, and teletherapy as a mode of service delivery being unlikely to go away after the pandemic, therapists require support in navigating crises situations online, in a medium that feels like the therapist has less control with their clients due to being in different physical locations. The authors believe that regardless of the primary model(s) therapists utilize in session, solution-focused brief therapy is an integrative model that uniquely captures client's resources and reasons for living and when clients are in crisis. The purpose of this paper is to present recommendations for applying solution-focused language in teletherapy practice, to provide ethical, evidenced based care for clients in crisis. A clinical vignette is used to illustrate the application of solution focused brief therapy for working with clients in crisis. Future directions and limitations are discussed.
\end{abstract}

Keywords SFBT $\cdot$ Suicide intervention $\cdot$ Teletherapy $\cdot$ Telemental health

\section{Introduction}

The world continues through a state of transition, grief, and trauma-management since COVID-19 halted what we knew of normalcy over a year ago. At the writing of this manuscript, over 8-million people have slipped into poverty and over 600,000 people have lost their life in the United States due to the pandemic and delayed federal and state response (CDC, 2021; DeParle, 2020). The World Health Organization (2020, October) found that across 160 countries, over $60 \%$ reported significant disruptions to mental health services for vulnerable people and over $67 \%$ experienced disruptions to counseling as a result form the pandemic. To provide care, therapists were left with three choices: face potential risk of COVID-19 exposure with in-person services, refer clients to someone providing in-person services, or jump headfirst into telehealth whether they were ready or not. The need for continuity of care is critical and the mental health field's relationship with telehealth is just beginning.

Benjamin T. Finlayson

Benjamin.Finlayson@ttu.edu

1 Department of Community, Family, \& Addiction Sciences, Texas Tech University, Lubbock, TX, USA
The COVID-19 pandemic thrust the mental health field into a digital world to provide continuity of care to their clients. Although the pandemic brought telemental health (TMH) services to the forefront of the mental health field, as a solution to delivering services while social distancing, the past two decades of research on TMH services has demonstrated that TMH is just as effective as in-person delivery and ready to meet the needs of therapists (Hilty et al., 2013; Rees \& Maclaine, 2015; Spence et al., 2011). The prospect of moving online may stir uneasy feelings for therapists around ethics, model transferability, and crisis intervention. Research from Springer et al. (2020) found that student therapists reported that the perceived lack of control over their [clients'] physical environment through teleplatforms impacted therapist confidence in managing crisis issues, such as suicidal ideation. Gaps still exist in our understanding of whether relational TMH services are effective (Caldwell et al., 2017) and best practices for training therapists in TMH practice (Pickens et al., 2020). National Public Radio (NPR, January 2021) reports that cases are showing promise of continued decline, however, fear of the latest mutation of the COVID-19 virus has health professionals fearful we will not be out of the woods any time soon. As such, clinician's relationship with telemental health is likely to continue. 
Through its flexibility and strengths-based care, the authors demonstrate how clinicians can integrate SFBT into their telemental health practice when working with clients with suicide ideation. The purpose of this paper is to offer current understandings of suicidality, issues in telemental health, outline and demonstrate the utilization of solution focused brief therapy in teletherapy crisis situations.

\section{Literature Review}

Death by suicide is a public health epidemic and requires a public, systemic change response. The American Foundation for Suicide Prevention (AFSP) reports on average, 129 Americans die by suicide each day (AFSP, 2019). The United States saw a significant increase in adults, adolescents, and children that died by suicide in 2018 from the year prior and it remains one of the ten leading causes of death (Leenaars et al., 2001; Pfeffers, 1986; Xu et al., 2018). Within and across minority groups, statistics indicate increased rates of suicide, specifically with ethnic, gender, and sexual orientation groups (Bridge et al., 2018; CDC, 2016; Herman et al., 2019; LeVasseur et al., 2013). These statistics highlight that marginalized groups in the United States are at an increased risk of suicide, and of additional concern, experience barriers for accessing services. Recently, the pandemic crisis has pulled support and isolated several from care. The Trevor Project, a non-profit dedicated to lesbian, gay, bisexual, transgender and queer suicide prevention, intervention, and education, reports a decrease in positive social interactions, employment loss, housing instability and increasing negative interactions for sexual and gender minority youths in the United States as a direct result from the pandemic (Green et al., 2020). Further, the CDC (2021) released a report stating that forty percent of adults in the United States experienced significant mental health concerns and over ten percent of adults reported significant thoughts of suicide shortly after the start of the pandemic (CDC, 2021). Though it is too soon to know the rates of death by suicide in 2020 and into 2021, the role of mental health professionals continues to be an essential need across the United States. As such, mental health professionals should have access to best-practice training and research that promotes the safety and well-being of their clients experiencing psychological distress.

\section{Intervention for Suicidal Thoughts and Behaviors}

Mental health professionals are positioned to lead discussion regarding prevention, intervention, and postvention of suicide that moves health professionals away from moral models of treatment and shifts towards system-based care that capitalizes on resources, (e.g., schools, communities), and taps into hope with their extensive training in affirming and relational models of behavior (Fiske, 2008; Leenaars et al., 2001). Intervention, the focus of this article, is the treatment and care of a suicidal crisis or problem. Traditional intervention methods, specifically safety planning where the client describes their plan while the therapist assesses for lethality and accessibility and results in the development of a "no suicide contract", raises contention among health care providers. Joiner and Silva (2012) have written that the use of traditional intervention methods encourage the client to recount their plan for suicide to a point of desensitization or demystification of dying by suicide and becomes, in turn, a rehearsal. Further, risk prediction has yet to provide an inventory of tools for clinical use and professionals have yet to agree nor match validity and reliability of self-assessment (Fiske, 2008). Understanding current best-practice in crisis intervention and how these practices translate into telemental health is critical to ensure that mental health professionals are providing the best care in the moment for their client experiencing severe suicidal thoughts and behaviors.

Clinician confidence may also impact the delivery of intervention methods. A systematic review of available literature on clinician confidence to carry out a suicide risk assessment found that of the 192 articles identified, only ten were relevant to the topic (Airey \& Iqbal, 2020). The ten identified articles by Airey and Iqbal (2020) suggested that clinician confidence was only slightly above fifty percent although statistical significance was only found in two of the studies in their review. Training with rural health providers demonstrated that stronger clinician confidence with suicidality correlated with an increased likeliness to incorporate newer best practices (LoParo et al., 2018). This suggests that the research on clinician's confidence in carrying out a suicide assessment in the moment is lacking and what exists does not offer strong direction for best practice to increase clinical competence and confidence. Despite extensive knowledge and years in mental health practice, clinicians still report a broad range of confidence in treating clients with suicidal thoughts, which suggests studies into what building clinician confidence when working with suicidal thoughts or behaviors and innovated interventions are still needed (Fruhbauerova \& Comtois, 2019). As clinicians shift toward teleplatforms 
or hybrid models of care, clinicians should be mindful of their current level of confidence offering telemental health and in what ways that may impact their delivery of crisis intervention services in session.

\section{Telemental Health Crisis Prevention and Intervention}

It is likely that working with clients struggling with suicide will be a concern among teletherapy providers, therefore professionals need to utilize teleservices in a way that is evidence-based, and suicide informed. Several modalities of online-based intervention have been studied and show promise for continued use and best-practice research. Online interventions designed to reduce stigma around suicide have been effective among adult populations, which could be promising for prevention efforts and help-seeking behaviors to normalize conversations around psychological distress (Rogers et al., 2018). Further, online preventative efforts for early intervention, such as online screening with personalized feedback and brief counseling, have been useful among young adults in college to engage in mental health services for suicidal ideation and distress (King et al., 2015). Asynchronous methods of intervention may be useful for those experiencing crisis as well. Unguided web-based interventions, such as e-mail, have shown strong correlations to participants reporting a decrease in suicidal ideation, hopelessness, anxiety, and depression than waitlist controls (Jaegere et al., 2019; Lester, 2008). Online group-chat rooms regulated by non-licensed professionals have presented over the last few years as a method of suicide prevention. Though these rooms are not regulated by a licensed professional, it is believed that the groups offer a space for individuals to create a supportive environment that will offer encouragement to seek help from a licensed professional (Gilat \& Shahar, 2009).

Though internet-based suicide efforts have shown strong reductions in stigma, hopelessness, and depression, direct telemental health delivery may hold the most significant impact for clients experiencing active distressing thoughts of suicide. Individuals more reluctant to seek in-person help from a professional, are more likely to utilize online or crisis line intervention support before utilizing face-to-face methods of support, including help from a friend or relative (Harris et al., 2009). Direct telemental health intervention for suicide with a live therapist continues to grow in research but present studies offer promising evidence for the benefits of web-based suicide prevention, particularly those that offered direct support (Lai et al., 2014). A small pilot study of adolescents enrolled in an internet intervention showed a significant decrease in overall levels of suicidal ideation, depression, and hopelessness (Robinson et al., 2016). Online interventions for suicidal ideation and depressive symptoms in adolescents are proven to be safe and acceptable and show significant relationships between distress levels at the start of treatment and decreased symptomology of both depression and anxiety immediately following treatment and at followup (Reyes-Portillo et al., 2014; Robinson et al., 2015). In a sample of 484 patients, internet delivered cognitive behavioral therapy (CBT) was effective at significantly reducing the prevalence of suicidal ideation and depression regardless of demographic variables (Mewton \& Andrews, 2015). This study demonstrates the use of a therapeutic model across teletherapy and its effectiveness for reducing depressive symptomology and suicidal ideation.

Like traditional face-to-face delivery, clinician confidence with suicidality may be impacted by the additional stressors of using a telehealth platform for delivery of care. A randomized controlled study analyzed deterioration rates of participants enrolled in a trial of online delivered CBT to reduce thoughts of suicide and found that internet-based programs are not harmful and showed lower rates of deterioration than in the control (Batterham et al., 2020). Using telehealth platforms with clients experiencing suicidal thoughts and behaviors may have certain risk or benefits for the client and therapist. A survey of mental health professionals found that lack of control was among the most common perceived risk of working with suicidal behaviors via telehealth platforms (Gilmore \& Ward-Ciesielski, 2019). Clinicians that have a stronger, more positive relationship toward telehealth platforms are more confident in delivering psychotherapy with patients experiencing suicidal moments (Gilmore \& Ward-Ciesielski, 2019). Teletherapy changes the way in which therapy is conducted, and not all models of therapy easily translate to online delivery, particularly crisis care (Springer et al., 2016). Solution focused brief therapy (SFBT) is a model that has an easier translation to teleservces. SFBT utilizes a post-structural, co-collaborative process to listen for, emphasize, and build on client's existing resources during intervention (de Jong \& Berg, 2013). SFBT is an efficacious model for crisis care across treatment sites and populations and offers a solution to address current concerns about existing suicide interventions.

\section{Solution Focused Brief Therapy}

SFBT's strengths-based focus is effective across treatment sites, presenting problems, and demographics for crisis care. In family therapy, solution focused therapy's post-structural lens (de Shazer, 1991) suggests that language crafts reality, change happens within language, and the language of the clients is what we must go on (de Shazer, 1994). SFBT is a flexible model that adapts to setting, e.g., schools, supervision (Thomas, 2013) and populations (Kokkvoll et al., 2013; Smock et al., 2011; Turns et al., 2016). Relevant to this 
article, research for SFBT shows its use for adult depression to be as good as other psychotherapies such as CBT, and for emotional, behavioral, and academic problems for youths in schools and family services (Kim \& Franklin, 2015; Franklin, 2015). Guided by several tenets, therapists utilize SFBT in a way that is most useful for them through the process of listen, select, build (de Jong \& Berg, 2013). Listen, select, build is a fluid structure of conducting therapy with SFBT. It guides the clinician through assessment, while listening to moments of difference, selecting them, and then building collaboratively with the client their preferred future (de Jong \& Berg, 2013). Regardless of professional training or preferred mental health modality, SFBT is a teachable model that can be effectively implemented when needed (Smith \& Macduff, 2017). In training clinicians across disciplines in SFBT, several stated that despite having different preferred models of therapy, they did not have to significantly change their philosophy toward client growth to successfully implement SFBT (Cunanan \& McCollum, 2006). These qualitative responses demonstrate that new or seasoned clinicians can still implement elements of strengths-based therapy without feeling as though they are losing their own unique style. Though SFBT is not practiced by all mental health professionals, we believe the model offers a strong foundation and transferability to telehealth platforms regardless of therapeutic modality preference, making it ideal for integration in crisis care.

\section{Solution Focused Brief Therapy and Psychological Distress}

Integrating solution-focused therapy has been an effective modality in crisis intervention in managed care treatment environments (Yeager, 2002). Case studies using solutionfocused specific methodologies, such as clarifying the problem and expanding solutions, shows clinical hope as a strategic intervention for clients experiencing suicidal thoughts and behaviors (Quick, 1998). For example, clinicians have successfully integrated SFBT in hospital emergency rooms with patients presenting with suicidal ideation to increase hope and agency; while maintaining appropriate care and discharge protocol (Kondrat \& Teater, 2010). Integrating SFBT into existing models of crisis treatment may have significant positive outcomes for the clients. Bannick (2008) outlined how traditional models of posttraumatic therapy work can shift toward posttraumatic success through implementing solution-focused approaches to trauma. Applying a solution focused approach to trauma engages conversations about what the client wants to see differently, and success is defined as the expansion of what the client wants rather than the lessening or ending of the problem; though that is also likely to occur in SFBT trauma work, it is not the primary focus (Bannick, 2008). Utilizing SFBT posttraumatic clinical training is an example of how wait time for services can be shortened, training is briefer, and the client is strengthened to undertake more positive action (Bannick, 2008). As SFBT maintains efficacy and appropriateness across presenting crisis concerns, research justifies its pragmatic transferability and application to teletherapy.

\section{Solution Focused Telemental Heath}

SFBT teletherapy is an effective method of treatment for several presenting problems: adolescents experiencing domestic violence (Georgiades, 2008), alcohol related problems in college students (Norman et al., 2018), and post-partum depression (Ondersma et al., 2007). Not only have the treatments been effective, but web-based SFBT chat interventions showed reliable and clinically significant change as well as similar effect sizes in pre-posttests with in-person treatment and even higher effect sizes four months later (Kramer et al., 2014). Participants in a randomized study of anxiety in college-age adults showed significant decreases in symptomology of anxiety in both the in-person and online delivery of SFBT psychotherapy treatment without significant differences between delivery methods (Novella et al., 2020). The process of client strength identification builds and reinforces the client-therapist partnership and allows a focus on competencies that the client already possesses to achieve their goals (Georgiades, 2008). These conversations can be had both in-person as well as through TMH and so the therapeutic relationship is not hindered by the delivery of services through technology.

A focus for SFBT therapists is identifying the strengths and competencies that their clients already possess. Solution-focused therapy allows clients to build upon their agency by respecting their personal assets, goals, and choice of intervention (Georgiades, 2008). These conversations do not depend on the client and the therapist being in the same room, instead they depend on the therapist's willingness to trust their client and allow them to lead. The ways in which SFBT therapists ask questions in and of itself is an intervention that translates well to TMH. A question such as, "What are some things you could start doing now that would help remind you of your reasons for living, just a little bit?" allows a client to identify the strengths they already possess and restores agency to continue to live their life.

\section{Solution Focused Telemental Health Crisis Intervention}

Solution focused therapy's evidence-based support across presenting concerns and telehealth modalities lends itself to be an immediate and pragmatic tool for therapists practicing teletherapy. Respondents of a SFBT tele counseling 
study reported that the model is easier to learn and that an almost immediate effect was noticed in their crisis client's reactions and positive thinking (Hsu et al., 2017). SFBT crisis telephone volunteers felt that SFBT was graspable and took the place of previously trained, less useful strategies, to shift clients toward goal formation and hope (Hsu et al., 2017). Further, a trial of an online SFBT chat treatment with adolescents experiencing significant depressive symptoms found statistically significant positive outcomes in mental health immediately following treatments and larger effects during follow-up (Kramer et al., 2014). An important shift for SFBT telehealth therapists is the language used when discussing suicide. For example, the researchers have used "died by suicide" rather than, "committed suicide," which suggests a loved one has died in the same way a crime is committed; "successful suicide," which implies that living would be a failure; or "completed suicide," which implies incompleteness (Fiske, 2008; Spencer-Thomas, 2018). Building toward co-constructive language, suggesting the client is "struggling with suicide" rather than are suicidal communicates that the clinician has hope about their future, believe in the capacity within themselves for change, and strengthens the therapeutic relationship across the screen (Fiske, 2008). This intentional and seemingly small change can impact how clinicians use suicidal crisis to focus on and promote pragmatic changes through teletherapy.

Therapists working with clients experiencing a crisis moment may feel unprepared to navigate that discussion across a TMH platform. Beyond ethical foundations, Gilmore and Ward-Ciesielski (2019) identified three clinical areas of concern when working with suicidal behaviors and thoughts across telehealth platforms: (1) assessment, (2) lack of control, and (3) triaging patients when/if needed. We discuss how integrating the structure of solution-focused therapy addresses these concerns to increase confidence while also demonstrating hope for their client's ability. Within SFBT, the three-step recursive co-constructive process of listen, select, build refers to the intentional focus on the client's language, their preferred futures, and exceptions to the problem, while avoiding assumptions about what the clients may be sharing (Bavelas et al., 2013). To demonstrate how SFBT delivered through TMH would utilize listen, select, build in suicide intervention, we will discuss each area of this process in detail and follow with a case vignette.

\section{(1) Assessment}

Initial conversations in solution-focused (SF) intervention disrupts the process of distress. The immediate challenge, or temptation, will be to enforce a problemsolving approach by jumping into a problem-assessment of how deeply in crisis the client is (de Jong \& Berg, 2013). A problem-assessment, or problem talk, may focus on questions about what led to feeling this way and what is the plan. The SF therapist, however, is a catalyst of change talk (Weiner-Davis, 1993). Asking specifically about desired change, "What needs to happen here so that when you look back on this meeting you can say it was helpful and a good idea to come here?" can interrupt the mental recursions that may lead to suicidal behavior. Listening to the client's perceptions while responding with empathic and affirming responses can offer a chance to amplify and examine their own perceptions (de Jong \& Berg, 2013).

A hallmark intervention in SFBT is the use of the miracle question. The clinician should know how they intended to use the miracle question before asking their client. When brought up in a broad sense, there is potential for the client to respond with, "Well, I would be dead." A response like this may startle a clinician. However valid a response, the clinician should validate and press further. For example, Insoo Kim Berg, the originator of the miracle question, asked a client dying with AIDS the miracle question. The client's response was that they would not have the disease, however, this is not a future that could be constructed. Insoo pressed further and the client responded about their will to die well (Berg, 1994). It is important for the therapist to go further and discuss what makes this solution a miracle to their problem and in doing so be listening for and selecting solution-focused language, exceptions to the problem, or strengths the client may have, etc. Wells and McCaig (2016) discussed utilizing the miracle question with adolescents in a medical setting and stressed that its effectiveness is best judged by the client. The miracle question demonstrates that the clinician is making significant efforts to see beyond the client's problem state while also addressing safety in the moment (Wells \& McCaig, 2016).

Assessing safety and lethality is a theme continuing throughout solution-focused crisis work and not a separate step because the solution-focused therapist is intently listening to what is important to the client, they are also listening for safety throughout the duration of the session (Greene et al., 1996). The SF therapist might remark, "Wow, it sounds like these thoughts have been so difficult. When was the last time you felt you were experiencing one of these more difficult days?" This can open assessment in a new way that aligns with the assumptions of SF therapy. While these questions validate the difficult and distressing nature of the suicidal thoughts, the therapist is also normalizing and seeking to identify whether the client has experienced them before and already overcame them without realizing. The SF therapist will also inquire about intensity and duration, while listening for times when the thoughts are not happening, "Oh, so it has been several 
weeks, and you were able to overcome those thoughts? Tell me how you did that." So, in effect, the SF therapist is constantly assessing for safety while simultaneously selecting moments of difference for the client that can be built upon through the TMH session.

Assessing exceptions and expanding possibilities can illuminate further pathways for clients. As Fiske (2008) describes, exceptions are not exceptional; they are happening all the time and should be sought after to build solutions. Utilization of scaling can direct these conversations through further assessment of what the client wants and how they are going to achieve that. For clients in crisis, using the scale to assess pre-session change may uncover stories of key reasons for living. With several telehealth platforms, features like a whiteboard or screen share may offer visualizations of the scaling process. The question may sound like, "On a scale of 0 to 10 , where 10 means you are experiencing all that you described earlier about what will be different, and 0 means how bad things were when you scheduled your appointment with me, please indicate on the whiteboard feature where would you say you are today from $0-10$ ?" Even if they client says " 0 " or perhaps even offers a negative number, the conversation that follows can offer useful assessment for how they still made it to the session despite having to work so hard to make that happen. Since TMH often takes place in the client's home, they may still be in bed, or have yet to shower leading the client to say, "I only left my house once, I haven't brushed my teeth, I just don't see the point." The therapist may highlight the one time they did leave the house, or even the thought about leaving, their awareness of their hygiene, and even their ability to $\log$ in for session.

(2) Challenging Assumptions of Control through Collaboration

As therapists, we risk sheltering ourselves with a false sense of security that we have control over what our clients do when they leave our room (even calls for triage can be denied by adults). When asking several training therapists what their biggest concern about TMH services, a common response was not being able to control the room in crisis type situations. We assume that by being in the same physical space for traditional therapy grants us control as session begins to get out of hand. However, because of our ethical codes and conducts there is truly little amounts of control that we have regardless of if session is in person or over teletherapy when it comes to these high stress situations. In both in-person and teletherapy services it is important for therapists to set boundaries and create rules for the therapeutic relationship that creates an environment that can feel controllable. While therapists have less control with teletherapy services, important steps can be taken to address issues of shifts in control. The therapist's view of clients experiencing a crisis may affect their perception of control as well. By viewing clients as in disequilibrium, we imply they are deficient in coping skills, nor do they have the skills to meet the challenge, which is further reinforced by most crisis intervention models that see clients as suffering irrational beliefs (Greene et al., 1996). To regain control, at least of our own processing, the therapist utilizing SFBT remembers the inevitability of change. By participating in the solution-building process and focusing on short-terms plans, solution focused conversations are more productive and empowering for clients (Jordan, 2014; de Jong \& Berg, 2013).

(3) Solution Focused Goals and Potential Triage

A SF goal is concrete, measurable, and achievable. SF goals should be client motivated and as specifically rich in detail as possible (Greene et al., 1996). Working with families in a solution-focused approach can be particularly beneficial during assessment, but also in building and maintaining goals. Utilizing family members may be useful to identity the time when the member struggling with suicide felt safe and what conditions facilitated those feelings (Softas-Nall \& Francis, 1998). Circular questions allow members to become aware of how interconnected they are through the feelings and actions of other members. It may become clear, however, after discussing with clients their best hopes, and their resources, that utilizing a resource around them, a friend or local clinic, may be necessary. Scaling goals, though it sounds counterintuitive, can help clients utilize their own agency to make choices that are best for the attainment of their goals, even if that means checking themselves into a clinic. Circular questioning, again, can help separate themselves from the problem they are experiencing, "If your cat were to say you are doing everything you need to do to make sure you are safe, what would you be doing?" Utilizing solution-focused interventions for suicide across teletherapy platforms offers therapists immediate, pragmatic linguistic tools to shift conversations for suicide toward hope-exposing, solution building conversations to help clients empower themselves for change.

\section{Case Vignette}

A fictionalized case vignette that incorporates real $\mathrm{TMH}$ case experiences is used to demonstrate how SFBT is utilized when working with clients struggling with suicide. This vignette uses a family's case to show how the therapist builds a sense of control, listens (assesses), and selects solution-building moments throughout treatment, and 
collaborates on goal creation. At first, we discuss more broad ideas and strategies that can be used for different types of clients, but we also provide brief transcripts to show specific ways that this clinician uses SFBT when working with suicidal ideation. The family is seeking services via distance, due to living in a mental health professional shortage area and the difficulty it is for them to drive the long distance to receive in person services. It is important to note that these services are being provided and received in the same state where the professional is licensed. Both parents live in the home and share three children. The son is wrestling with serious psychological distress and suicidal thoughts.

Julia (42) initiated therapy services in a very distraught place, because in her words, she had just found out her 15-year-old son had tried to "commit suicide." During the intake session she and her husband Robert (45) share that they have been married for 20 years, have three children: 18-year-old daughter, 15-year-old son (Wesley), and an 8 -year-old son (all still in the home, but not present during the session). Both have steady careers now that all their children are in school, they identify as religious and attend services at least monthly, are upper middle class, and are both European American. Julia does the majority of the talking in session and explains how easy their life was until two years ago when Wesley came out to them and has since battled depression and thoughts of suicide. This battle culminated the past week when he sat down and had a serious conversation with his father about no longer wanting to be on the earth. He shared how scared he was about these thoughts, but that they felt somewhat safe to say. After the initial meeting, the therapist decides to meet with Julia, Robert, and their son Wesley.

We must first address that teletherapy presents the challenge of how to properly conduct assessments, provide interventions, and evaluate treatment, with therapists citing concerns such as: the emotional climate of the room, a lack of body language recognition, and the ability to observe the room as one person speaks (Gilmore \& Ward-Ciesielski, 2019). Though these concerns are both real and valid, guidelines for addressing logistical concerns exist to support therapists in providing teletherapy services. Luxton and colleagues (2016) have outlined logistical considerations that addresses these concerns in greater depth, but therapists should consider the placement of the camera and the quality of technology and bandwidth which can influence the ability to properly conduct teletherapy assessments.

\section{Lack of Control}

A major concern therapists raise is not feeling in control when providing teletherapy. This is a valid concern if one is unfamiliar with TMH and steps that can be taken to give a sense of control and predictability. Like new therapists being concerned with controlling the therapy room because of a lack of experience, seasoned therapists may feel concerned, because of a lack of exposure to TMH. As a way to gain some of that control Luxton and colleagues (2016), created a risk management form. This form is a one-page document that identifies an emergency contact person, the nearest hospital, the local emergency number, and re-states the client's address for ease of access. As a SF therapist we shift our language from risk management to resource form. The use of a resource form gives clinicians a document that can be used in moments of crisis when outside resources need to be used in a therapy session. These contacts are necessary when providing services from a distance, because without them the clinician will not be equipped to handle crisis situations.

Providing the client with the opportunity to identify resources in their community allows them to see their own strength in creating an action plan for support. As the therapist asks questions such as "Who would you need to reach out to in order to receive the care and support you need?" or "Who in your life have you reached out to in the past that was helpful in overcoming trials or challenges?" The second question highlights finding exceptions in the client's life that at times may not be in the forefront of their memory. The resource form would be used by the family during times of crisis, or by the SF therapist should a crisis occur during session that the SF therapist could not address due to geographical distance or severity of the concern.

As we think about the family, the clinician sits down with Julia, Robert, and Wesley and invites them each to think about individuals that they have reached out to in the past who have helped them through tough times. Through this exercise, the mother and father were able to identify family friends that were helpful, but Wesley seemed to struggle identifying someone he has turned to. The therapist can also utilize an adapted form of the miracle question and ask, "In a perfect world, who would you want to reach out to in these moments?" This type of question keeps Wesley's thought process on potential solutions rather than focusing on what has not worked to this point. This type of intervention gives the therapist security knowing that the clients have a close support system, while also setting the tone for therapy's focus on solutions and showing the clients that they have it within themselves to come up with their own solutions. These SF questions support the completion of the resource form and following completion the therapist and the family retain copies. The therapist can use scaling questions to gauge when and where the family will use their resource form. Such discussions serve to further empower the client by giving them the choice when it is and is not appropriate to reach out. 


\section{Assessment}

SF therapist should implement scaling questions as a chance to give the client a sense of autonomy and responsibility for their own change process. These questions not only allow the client to reflect on their status, but it gives the therapist valuable information about the status of their clients. A SF therapist does this to listen and select the information that is most important either to the client or to the safety of the client. To further assess for safety, the therapist can invite the clients to identify ways in which they could take a step or half a step forward and go from one number to the next number. Such a question keeps the client focused on solutions and the therapist can gain further assessment information about safety from client's responses. If clients struggle to identify steps or cannot identify a step, the therapist knows that reaching out to external help may be necessary. This is when the therapist can remind the client of their resource form and scale whether the client needs to reach out to their emergency contacts.

For example, "Wesley, I want you to think about that moment when you felt so low the only thing you could do was talk to your dad. I want you to label that moment as a 10 . On a scale from 1 , no troubling thoughts, and 10 talking to your dad, where would you rate your emotional state right now?" Wesley responds and says, "Honestly, right now I feel like I am at a five or six." The therapist then asks, "Tell me more about that." Wesley expands for several minutes about the struggles he is having with friends at school, because he has not felt comfortable sharing his sexual orientation with anyone at school. He explains that the people at school will stop talking to him, will look at him differently, or bully him, not to mention no one in his school is gay, so there is no point to share. The therapist notices that Wesley has not shared any exceptions, strength, or solution type language and asks a direct question about that. "So, Wesley thank you so much for sharing with me, I am curious you were willing to share your feelings with your parents, what made you want to share with them?" The purpose for asking this question was to shift Wesley's thoughts and allow his brain to identify strengths in the relationships that he already has. After Wesley responds, the therapist selects the feelings of trust he has with his parents and asks, "What did you and your parents do to create feelings of trust?" Here, the therapist may also decide to ask mom and dad to answer. As they answer, the therapist allows Wesley to respond and build that connection with mom and dad.

Towards the end of this conversation, the family has been able to identify several people in Wesley's life that he can reach out to and be congruent with. This conversation appears to have really lifted the spirits in the room and now the therapist ask a scaling question directed to the parents, "Now that we have identified people we can reach out to when we feel out of control, on a scale from 1 to 10,10 being the most comfortable you have felt about your situation and 1 being last week when you reported feeling no comfort or control, where would you rate your comfort or control level?" Wrapping the conversation up in this way helps the clients see the progress that has been made and the feelings of hope that they can have towards the future.

\section{Building Concrete Goals}

Integral to the change process is the client's ability to set clear, measurable, and attainable goals with the assistance of the therapist. As a post-structural model of therapy SF therapists understand that their own reality and their client's reality are shaped by individual experiences. With this assumption, the therapist strives to remain curious as the clients share their perspectives. This curiosity pushes therapists to avoid assuming what clients mean when they attribute a value to something, like, "I just want to feel better." The therapist instead of saying, "Great, and how will we feel better?" might say something like, "What does it look like to feel better for you?" The slight variation in this question allows the client to build their reality and do so in a way that allows the therapist to understand the situation more fully. In addition to this curious stance and its influence on language an SF therapist advocates for clients to create their own goals in session. Just as the therapist cannot assume what is meant by the word "good" they also cannot assume to know what the client needs to improve. The therapist is aware that goals should be clear, measurable, and attainable and plays a role in forming such goals for the client.

As the therapist works with Wesley and his parents, they can invite Wesley to identify what goals he would like to set and reach. This can be done through exception-based questions like "What times in your life have you thought less about suicide?" With a question like this, Wesley can reflect on his experiences and identify times that he has been living his preferred solution. Wesley may say something like, "I just didn't have to think about being different, it wasn't even a thought in my head." The therapist may ask, "Tell me more about that." Wesley could say something, "Once I started to question my sexuality, I realized that most people are not like me and that I was different than my friends." The therapist could validate Wesley in this moment and then ask, "How would you like to be thinking now?" Wesley responds with, "I wouldn't be thinking I am different I would just be thinking, I am normal." Taking a curious stance the therapist asks, "What does it mean for you to be normal?" This allows Wesley to express his feelings, process his thoughts, and clarify what it is he might want. After exploring what normal might look like for Wesley, the therapist can then ask, "Have there been times since you talked to your parents that things felt "normal" like the way you have described? 
What about those times is different, or what were you doing differently in this moment that allowed you to think differently?" The goal can then be created by identifying which behaviors are different and increasing those behaviors in a clear and measurable way. For example, Wesley could say that when he spends time reading and writing things start to feel normal for him and does not feel such a strong desire to end his life. So, a goal might be for Wesley to read and write every night before bed or at times when he recognizes feeling different.

Throughout this vignette we have shown ways in which SFBT interventions can be used through technology in such a way that is not different from in-person interventions. These interventions should address some of the main concern's (e.g., lack of control, inability to recognize body language, etc.) therapists have with TMH services and give them confidence in working with crisis situations.

\section{Additional Clinical Considerations}

Telemental health is a new mode of service delivery for some practitioners. As such, the authors encourage each clinician practicing TMH to research their state-specific laws concerning the delivery of therapy through online platforms. States may vary on jurisdictional best practices. For example, if a practitioner is licensed in the state of Texas yet vacationing in South Carolina, what are the state laws governing the delivery of mental health via teleplatforms for both states. Similarly, if a client is receiving services in their home state of Maine, but wish to receive services when traveling out of state for business, what does Maine's regulations state about out of state telepractice? It is important that the clinicians know these laws as it is not the responsibility of the client to ensure best practice. Further, clinicians who hold licenses in multiple states should investigate state mandated reporting laws for each state of practice. These laws should be discussed with other clinicians and incorporated into intake documents or into emergency telemental health protocol documents. Including these practices into clinical forms before meeting with client's allows the clinician to bring emergency protocols into the room before a crisis happens.

For professionals less familiar with SFBT, our brief overview may leave a few questions unanswered. One of those questions is likely the limitation of SFBT frequently discussed: its relationship with emotions and change. Those just learning or unfamiliar with the model may find it cold and rather detached, as it does not draw upon emotions as the center-force for change. Rather, SF therapists utilize emotion as another resource that is associated with desired behavior. Further, new SF practitioners may fool themselves into thinking that their client's problem talk should be avoided.
On the contrary, it can be within the problem talk that we are able to listen and select what clients want. This process can solidify the therapeutic relationship through joining while also honoring the change process, noticing a shift. Another misunderstanding about SFBT is the assumption that SF language is problem solving. Understandably so. Solution focused therapy, however, is deliberate and persistent co-constructive conversations about what the clients want because of therapy, despite their presenting concern. To clarify, it is not ignoring the problem, it is coming back to it in a way that shifts our relationship with our own agency to do something different. Finally, therapists frequently cite concerns over "What to do if a client in crisis logs off of session during a crisis moment in session?" Therapists should be proactive in discussing a range of situations in which the Resource Form will be used, by both the clients and the therapist. Collaborative discussions about how the therapist will use the Resource Form if the client logs off session while in crisis should be agreed upon, providing the therapist with a clear plan of action.

\section{Limitations and Future Directions}

Although we propose that SFBT delivered over teletherapy is appropriate for addressing crisis situations, therapists should develop criteria to determine whether teletherapy is the appropriate modality for receiving services. We recognize that teletherapy is not suitable for all clients, and therefore, therapists must consider suitability of teletherapy services on a case-by-case basis. Research should be conducted to identify whether there are factors (e.g., age, severity of struggling with suicide, historical factors) that should guide decisions about use of teletherapy to provide services during crisis. Additionally, utilizing SFBT across teletherapy platforms needs to be extensively studied with attention paid to longitudinal design and qualitative methods to assess thematic shifts in language and the process of change across teleplatforms. Further, the authors would like to see SF suicide intervention applied to prevention, intervention, and postvention suicide education not only within traditional mental health practices, but within integrated settings, such as collaborative health care. The authors are passionate that the language used in solution focused care has the potential to not only help clients save themselves but also create a ripple effect in how professionals can play an active role in suicide prevention.

Funding Not Applicable.

Data Availability Not Applicable.

Code Availability Not Applicable. 


\section{Declarations}

Conflict of Interest Not Applicable.

\section{References}

Airey, N. D., \& Iqbal, Z. (2020). Are clinicians confident in the risk assessment of suicide: A systematic literature review. Archives of Suicide Research. https://doi.org/10.1080/13811118.2020.17920 19

American Foundation for Suicide Prevention (AFSP). (2019). Suicide facts \& figures: United States 2019. https://www.datocms-assets. com/12810/1582813931-usfactsfiguresflyer.pdf

Bannick, F. P. (2008). Posttraumatic success: Solution-focused brief therapy. Brief Treatment and Crisis Intervention, 8(3), 215-225. https://doi.org/10.1093/brief-treatment/mhn013

Batterham, P. J., Christensen, H., Calear, A. L., Werner-Seidler, A., \& Kazan, D. (2020). Rates and predictors of deterioration in a trial of internet-delivered cognitive behavioral therapy for reducing suicidal thoughts. Archives of Suicide Research. https://doi.org/ 10.1080/13811118.2020.1848671

Bavelas, J., De Jong, P., Franklin, C., Froerer, A., Gingerich, W., Langer, S., Lee, M. Y., McCollum, E. E., Jordan, S. S., \& Trepper, T. (2013). Solution focused therapy treatment manual for working with individuals (2nd ed.). https://doi.org/10.1093/acprof: oso/9780195385724.003.0015

Berg, I. K. (1994). Dying well. Brief Family Therapy Center.

Bridge, J. A., Horowitz, L. M., Fontanella, C. A., Sheftall, A. H., Greenhouse, J., Kelleher, K. J., \& Campo, J. V. (2018). Agerelated racial disparity in suicide rates among US youths from 2001 through 2015. JAMA Pediatrics, 172(7), 697-699. https:// doi.org/10.1001/jamapediatrics.2018.0399

Caldwell, B. E., Bischoff, R. J., Derrig-Palumbo, K. A., \& Liebert, J. D. (2017). Best practices in the online practice of couple and family therapy [PDF file]. Retrieved from https://www.aamft.org/Docum ents/Products/AAMFT_Best_Practices_for_Online_MFT.pdf

Center for Disease Control (CDC). (2016). Adolescent Health. https:// www.cdc.gov/nchs/fastats/adolescent-health.htm

Center for Disease Control (CDC). (2021). COVID Data Tracker. https://covid.cdc.gov/covid-data-tracker/\#datatracker-home

Cunanan, E. D., \& McCollum, E. E. (2006). What works when learning solution-focused brief therapy: A qualitative study of trainees' experiences. Journal of Family Psychotherapy, 17(1), 49-65. https://doi.org/10.1300/J085v17n01_04

de Jong, P., \& Berg, I. K. (2013). Interviewing for solutions. Brooks/ Cole.

de Shazer, S. (1991). Putting difference to work. W. W. Norton \& Company Inc.

de Shazer, S. (1994). Words were originally magic. W. W. Norton \& Company Inc.

DeParle, J. (2020) 8 Million Have Slipped into Poverty Since May as Federal Aid has Dried Up. The New York Times. https://www. nytimes.com/2020/10/15/us/politics/federal-aid-poverty-levels. html

Fiske, H. (2008). Hope in action: Solution-focused conversations about suicide. Routledge.

Franklin, C. (2015). An update on strengths-based solution-focused brief therapy. National Association of Social Workers. https://doi. org $/ 10.1093 / \mathrm{hsw} / \mathrm{hlv022}$

Fruhbauerova, M., \& Comtois, K. A. (2019). Addiction counselors and suicide: Education and experience do not improve suicide knowledge, beliefs, or confidence in treating suicidal clients. Journal of
Substance Abuse Treatment, 106, 29-34. https://doi.org/10.1016/j. jsat.2019.08.012

Georgiades, S. D. (2008). A solution-focused intervention with a youth in a domestic violence situation: Longitudinal Evidence. Contemporary Family Therapy, 30, 141-151. https://doi.org/10.1007/ s10591-008-9067-1

Gilat, I., \& Shahar, G. (2009). Suicide prevention by online support groups: An action theory-based model of emotional first aid. Archives of Suicide Research, 13, 52-63. https://doi.org/10.1080/ 13811110802572148

Gilmore, A. K., \& Ward-Ciesielski, E. F. (2019). Perceived risks and use of psychotherapy via telemedicine for patients at risk for suicide. Journal of Telemedicine and Telecare. https://doi.org/10. 1177/1357633X17735559

Green, A. E., Price-Feeney, M., \& Dorison, S. H. (2020). Implications of COVID-19 for LGBTQ youth mental health and suicide prevention. The Trevor Project.

Greene, G. J., Lee, M., Trask, R., \& Rheinscheld, J. (1996). Client strengths and crisis intervention: A solution-focused approach. Crisis Intervention, 3(1), 43-63. https://doi.org/10.1606/10443894.3538

Harris, K. McLean, J., \& Sheffield, J. (2009). Solving suicidal problems online: Who turns to the internet for help? Australian e-Journal for the Advancement of Mental Health, 8(1). www.auseinet.com/ journal/vol8iss 1/harrismclean.pdf

Hilty, D. M., Ferrer, D. C., Parish, M. B., Jonston, B., Callahan, E. J., \& Yellowlees, P. M. (2013). The effectiveness of telemental health: A 2013 review. Telemedicine Journal and E-Health, 19(6), 444-454. https://doi.org/10.1089/tmj.2013.0075

Herman, J. L., Brown, T. N. T., \& Haas, A. P. (2019) Suicide thoughts and attempts among transgender adults in the US. UCLA School of Law Williams Institute

Hsu, W., Lin, H., Sun, S. M., \& Chen, H. (2017). The training effects of solution-focused brief counseling on telephone-counseling volunteers in Taiwan. Journal of Family Psychotherapy, 28(4), 285-302. https://doi.org/10.1080/08975353.2017.1297066

Jaegere, E. D., van Landschoot, R., van Heeringen, K., van Spijker, B. A. J., Kerkhof, J. F. M., Mokkenstorm, J. K., \& Portzky, G. (2019). The online treatment of suicidal ideation: A randomized controlled trial of an unguided web-based intervention. Behaviour Research and Therapy. https://doi.org/10.1016/j.brat.2019.05.003

Joiner Jr., T. E., \& Silva, C. (2012). Why people die by suicide: Further development and test of the interpersonal-psychological theory of suicidal behavior. In P. R. Shaver \& M. Mikulincer (Eds.), Meaning, mortality, and choice: The social psychology of existential concerns (pp. 325-336). American Psychological Association. https://doi.org/10.1037/13748-018

Jordan, S. S. (2014). Asking different questions: Validation of the solution building inventory in a clinical sample. Journal of Systemic Therapies, 33(1), 78-88. https://doi.org/10.1521/jsyt.2014.33.1.78

Kim, J. S., \& Franklin, C. (2015). Understanding emotional change in solution-focused brief therapy: Facilitating positive emotions. Best Practices in Mental Health, 11(1), 25-41.

King, C. A., Eisenberg, D., Zheng, K., Czyz, E., Kramer, A., Horwitz, A., \& Chermack, S. (2015). Online suicide risk screening and intervention with college students: A pilot randomized controlled trial. Journal of Consulting and Clinical Psychology, 83(3), 630636. https://doi.org/10.1037/a0038805

Kokkvoll, A., Grimsgaard, S., Odegaard, R., Flagstad, T., \& Njolstad, I. (2013). Single versus multiple-family intervention in childhood overweight - Finnmark Activity School: A randomized trial. Archives of Disease in Childhood. https://doi.org/10.1136/archd ischild-2012-303571

Kondrat, D. C., \& Teater, B. (2010). Solution-focused therapy in an emergency room setting: Increasing hope in persons presenting 
with suicidal ideation. Journal of Social Work, 12(1), 3-15. https://doi.org/10.1177/1468017310379756

Kramer, J., Conijn, B., Oijevaar, P., \& Riper, H. (2014). Effectiveness of a web-based solution-focused brief chat treatment for depressed adolescents and young adults: Randomized controlled trial. Journal of Medical Internet Research. https://doi.org/10. 2196/jmir.3261

Lai, M. H., Maniam, T., \& Chan, L. F. (2014). Caught in the web: A review of web-based suicide prevention. Journal of Medical Internet Research. https://doi.org/10.2196/jmir.2973

Leenaars, A., Wenckstern, S., Appleby, M., Fiske, H., Grad, O., Kalafat, J., Smith, J., \& Takahashi, Y. (2001). Current issues in dealing with suicide prevention in schools: Perspectives from some countries. Journal of Education and Psychological Consultation, 12(4), 362-384. https://doi.org/10.1207/S1532768XJ EPC1204_04

Lester, D. (2008). The use of the internet for counseling the suicidal individual: Possibilities and drawback. Omega, 58(3), 233-250. https://doi.org/10.2190/OM.58.3.e

LeVasseur, M. T., Kelvin, E. A., \& Grosskopf, N. A. (2013). Intersecting identities and the association between bullying and suicide attempt among New York city youths: Results from the 2009 New York city youth risk behavior survey. American Journal of Public Health, 103(6), 1082-1089. https://doi.org/ 10.2105/AJPH.2012.300994

LoParo, D., Florez, I. A., Valentine, N., \& Lamis, D. A. (2018). Associations of suicide prevention trainings with practices and confidence among clinicians at community mental health centers. Suicide and Life-Threatening Behavior, 49(4), 1148-1156. https://doi.org/10.1111/sltb.12498

Luxton, D. D., Nelson, E. L., \& Maheu, M. M. (2016). A practitioner's guide to telemental health. APA.

Mewton, L., \& Andrews, G. (2015). Cognitive behavior therapy via the internet for depression: A useful strategy to reduce suicidal ideation. Journal of Affective Disorders, 170, 78-84. https://doi. org/10.1016/j.jad.2014.08.038

National Public Radio (NPR) (2021, January 21). Current, deadly U.S. coronavirus surge has peaked, researchers say. https:// www.npr.org/sections/health-shots/2021/01/21/958870301/ the-current-deadly-u-s-coronavirus-surge-has-peaked-resea rchers-say

Norman, P., Cameron, D., Epton, T., Webb, T. L., Harris, P. R., Millings, A., \& Sheeran, P. (2018). A randomized controlled trial of a brief online intervention to reduce alcohol consumption in new university students: Combining self-affirmation, theory of planned behavior messages, and implementation interventions. British Journal of Health Psychology, 23, 108-127. https://doi. org/10.1111/bjhp.12277

Novella, J. K., Ng, K., \& Samuolis, J. (2020). A comparison of online and in-person counseling outcomes using solutionfocused brief therapy for college students with anxiety. Journal of American College Health. https://doi.org/10.1080/07448481. 2020.1786101

Ondersma, S. J., Svikis, D. S., \& Schuster, C. R. (2007). Computerbased brief intervention: A randomized trial with postpartum women. American Journal of Preventive Medicine. Doi: https:// doi.org/10.1016/j.amepre.2006.11.003

Pfeffer, C. R. (1986). Suicide prevention: Current efficacy and future promise. Annals of the New York Academy of Sciences. https://doi. org/10.1111/j.1749-6632.1986.tb27912.x

Pickens, J. C., Morris, N., \& Johnson, D. J. (2020). The Digital Divide: Couple and Family Therapy Programs' Integration of Teletherapy Training and Education. Journal of Marital and Family Therapy, 46(2), 186-200. https://doi.org/10.1111/jmft.12417

Quick, E. K. (1998). Strategic solution focused therapy: Doing what works in crisis intervention. Crisis Intervention, 4(2-3), 197-214.
Rees, C. S., \& Maclaine, E. (2015). A systematic review of videoconference-elivered psychological treatment for anxiety disorders. Australian Psychologist, 50(4), 259-264. https://doi.org/10.1111/ ap. 12122

Reyes-Portillo, J. A., Mufson, L., Greenhill, L. L., Gould, M. S., Fisher, P. W., Tarlow, N., \& Rynn, M. A. (2014). Web-based intervention for youth internalizing problems: A systematic review. Journal of the American Academy of Child \& Adoles cent Psychiatry, 53(12), 1254-1270. https://doi.org/10.1016/j. jaac.2014.09.005

Robinson, J., Hetrick, S., Cox, G., Bendall, S., Yung, A., \& Pirkis, J. (2015). The safety and acceptability of delivering an online intervention to secondary students at risk of suicide: Findings from a pilot study. Early Intervention Psychiatry, 9(6), 498506. https://doi.org/10.1111/eip.12136

Robinson, J., Hetrick, S., Cox, G., Bendall, S., Yuen, H. P., Yung, A., \& Pirkis, J. (2016). Can an internet-based intervention reduce suicidal ideation, depression and hopelessness among secondary school students: Results from a pilot study. Early Intervention in Psychiatry, 10, 28-35. https://doi.org/10.1111/eip.12137

Rogers, M. L., Schneider, M. E., Gai, A. R., Gorday, J. Y., \& Joiner, T. E. (2018). Evaluation of two web-based interventions in reducing the stigma of suicide. Behavior Research and Therapy, 109, 49-55. https://doi.org/10.1016/j.brat.2018.08.001

Smith, S., \& Macduff, C. (2017). A thematic analysis of the experience of UK mental health nurses who have trained in solution focused brief therapy. Journal of Psychiatric and Mental Health Nursing, 24(1), 105-113. https://doi.org/10.1111/jpm.12365

Smock, S. A., Froerer, A. S., \& Blakeslee, S. E. (2011). Systemic interventions in substance-abuse treatment: Past present and future. Journal of Family Psychotherapy, 22(3), 177-192. https://doi.org/ 10.1080/08975353.2011.602613

Softas-Nall, B. C., \& Francis, P. C. (1998). A solution-focused approach to suicide assessment and intervention with families. The Family Journal: Counseling and Therapy for Couples and Families. Doi: https://doi.org/10.1177/1066480798061014

Spence, S. H., Donovan, C. L., March, S., Gamble, A., Anderson, R. E., Prosser, S., et al. (2011). A randomized controlled trail of online versus clinic-based CBT for adolescent anxiety. Journal of Consulting and Clinical Psychology, 79(5), 629-642. https:// doi.org/10.1037/a0024512

Spencer-Thomas, S. (2018, June). Language matters: Why we don't say "committed suicide". IRMI. https://www.irmi.com/articles/ expert-commentary/language-matters-committed-suicide

Springer, P., Bischoff, R. J., \& KohelTaylorFarero, K. N. C. A. (2020). Collaborative Care at a distance: Student therapists' experiences of learning and delivering relationally focused telemental health. Journal of Marital and Family Therapy, 46(2), 201-217. https:// doi.org/10.1111/jmft.12431

Springer, P., Farero, A., Bischoff, R. J., \& Taylor, N. C. (2016). Using experiential interventions with distance technology: Overcoming traditional barriers. Journal of Family Psychotherapy, 27(2), 148-153. https://doi.org/10.1080/08975353.2016.1169028

Thomas, F. (2013). Solution-focused supervision: Lessons from Insoo Kim Berg. In P. de Jong \& I. K. Berg, Interviewing for Solutions (4th ed.). Brooks/Cole.

Turns, B., Eddy, B. P., \& Jordan, S. S. (2016). Working with siblings of children with autism: A solution-focused approach. Australian \& New Zealand Journal of Family Therapy, 37(4), 558-571. https:// doi.org/10.1002/anzf.1183

Weiner-Davis, M. (1993). Pro-constructed realities. In S. Gilligan \& R. Price (Eds.), Therapeutic conversations (pp. 149-160). Norton $\&$ Co.

Wells, K., \& McCraig, M. (2016). The magic wand question and recovery-focused practice in child and adolescent mental health 
services. Journal of Child and Adolescent Psychiatric Nursing, 29, 164-170. https://doi.org/10.1111/jcap.12159

World Health Organization (WHO). (2020, October 5). COVID-19 disrupting mental health services in most countries, WHO survey. https://www.who.int/news/item/05-10-2020-covid-19-disruptingmental-health-services-in-most-countries-who-survey

Xu, J.Q., Murphy, S.L., Kochanek, K.D., \& Arias, E. (2018). Mortality in the United States, 2018. NCHS Data Brief, no 355. Hyattsville, MD: National Center for Health Statistics. 2020.

Yeager, K. R. (2002). Crisis intervention with mentally ill chemical abusers: Application of brief solution-focused therapy and strengths perspective. Brief Treatment and Crisis Intervention, 2, 197-216. https://doi.org/10.1093/brief-treatment/2.3.197

Publisher's Note Springer Nature remains neutral with regard to jurisdictional claims in published maps and institutional affiliations. 